\title{
Caracterização físico-química e microbiológica da farinha de algaroba (Prosopis juliflora (Sw.) DC)
}

Physicochemical and microbiological characterization of mesquite flour (Prosopis juliflora (Sw.) DC)

\author{
Celiane Gomes Maia da SILVA ${ }^{1}$, Artur Bibiano de MELO FILHO ${ }^{2}$, \\ Edleide Freitas PIRES², Tânia Lúcia Montenegro STAMFORD²*
}

\begin{abstract}
Resumo
Algaroba (Prosopis juliflora (Sw.) D.C.) é uma leguminosa arbórea tropical comum no semi-árido brasileiro e desenvolve-se em lugares secos, onde dificilmente outras plantas poderiam sobreviver. Suas vagens produzem uma farinha que pode ser usada na alimentação humana, além de vários outros produtos como o mel, licor e um produto similar ao café. Este trabalho teve por objetivo caracterizar quanto à composição físico-química e microbiológica a farinha de algaroba potencialmente passível de introdução como matéria-prima de interesse comercial. A farinha de algaroba foi analisada quanto ao teor de umidade, cinzas, proteína, lipídios, açúcares totais, açúcares redutores, fibra alimentar total e tanino. Os minerais analisados foram cálcio, fósforo, magnésio, ferro, zinco, sódio, potássio, manganês, silício, alumínio e cobre. As análises microbiológicas foram: coliformes a $45{ }^{\circ} \mathrm{C} . \mathrm{g}^{-1}$, Bacillus cereus.g ${ }^{-1}$, Salmonella sp..25 g $\mathrm{g}^{-1}$, e bolores e leveduras.g $\mathrm{g}^{-1}$. Verificou-se que a farinha de algaroba apresenta elevados níveis de açúcares (56,5 g. $\left.100 \mathrm{~g}^{-1}\right)$, razoável teor de proteínas $\left(9,0\right.$ g. $\left.100 \mathrm{~g}{ }^{-1}\right)$ e baixo teor em lipídios $\left(2,1 \mathrm{~g} 100 \mathrm{~g}^{-1}\right)$. Quanto aos minerais observou-se a predominância do fósforo $\left(749 \mathrm{mg} .100 \mathrm{~g}^{-1}\right)$ e do cálcio $\left(390 \mathrm{mg}\right.$. $\left.100 \mathrm{~g}{ }^{-1}\right)$. As análises microbiológicas apresentaram resultados inferiores ao limite estabelecido pela legislação, sendo considerada apropriada quanto à qualidade higiênico-sanitária. Portanto, conclui-se que esta possui uma elevada concentração de açúcares além de outros nutrientes, como minerais, importantes para o desenvolvimento humano e animal.

Palavras-chave: leguminosa; valor nutritivo; segurança microbiológica.
\end{abstract}

\begin{abstract}
Mesquite (Prosopis juliflora (Sw.) D.C.) is a tropical tree legume fairly common in the semi-arid region of Brazil, which thrives in dry environments where other plants would hardly survive. Its seedpods can be made into flour, which is used in human food and other products such as honey, liqueur and a product similar to coffee. The major aim of this study was to characterize the physicochemical and microbiological composition of mesquite flour with a view to introducing it as a commercial raw material. The mesquite flour was analyzed to determine its water, ash, protein, lipids, total sugar, reducing sugar, total food fiber and tannin content. The minerals analyzed were calcium, phosphorous, magnesium, iron, zinc, sodium, potassium, manganese, silicon, aluminum and copper. The microbiological analysis focused on coliforms at $45{ }^{\circ} \mathrm{C} . \mathrm{g}^{-1}$, Bacillus cereus.g ${ }^{-1}$, Salmonella sp..25 $\mathrm{g}^{-1}$ and molds and yeasts. $\mathrm{g}^{-1}$. The mesquite flour presented high levels of sugars $\left(56.5 \mathrm{~g} .100 \mathrm{~g}^{-1}\right)$, a moderate level of proteins $\left(9.0 \mathrm{~g} .100 \mathrm{~g}^{-1}\right)$ and low levels of lipids $\left(2.1 \mathrm{~g} .100 \mathrm{~g}^{-1}\right)$. As for mineral content, the results showed a prevalence of phosphorous (749 mg. $100 \mathrm{~g}^{-1}$ ) and calcium (390 mg. $100 \mathrm{~g}^{-1}$ ). The microbiological analysis showed results below the legal limits, allowing the product to be considered appropriate from a sanitary standpoint. It was therefore concluded that mesquite flour contains a high concentration of sugars as well as other nutrients such as minerals, which are important for human and animal development.
\end{abstract}

Keywords: legume; nutritional value; microbiological safety.

\section{Introdução}

O gênero Prosopis pertence à família Leguminosae, subfamília Mimosoideae e tem cerca de 44 espécies. São arbustos de tamanho médio ou árvores de grande porte, que podem atingir 20 metros de altura, com tronco de mais de um metro de diâmetro. Embora cresçam nas proximidades de água, diferentes espécies de Prosopis desenvolvem-se em lugares secos, onde dificilmente outras plantas poderiam sobreviver. Ainda podem tolerar e crescer com rapidez em solos salinos e em solos ácidos de baixa fertilidade ${ }^{9}$.

De grande rusticidade, a algarobeira (Prosopis juliflora (Sw.) D.C.), espécie originária do deserto de Piura no Peru, apresenta

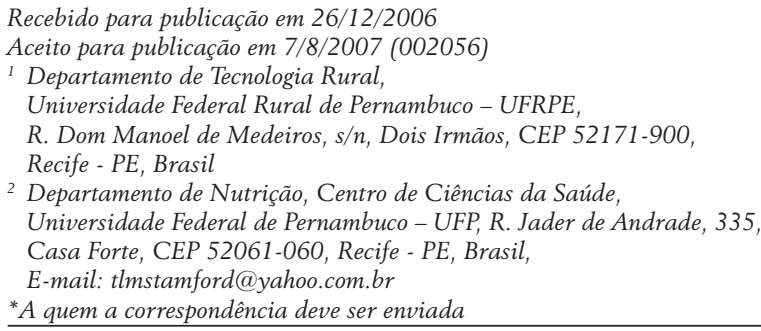

características que justificam a sua utilização nas áreas áridas e semi-áridas do Nordeste brasileiro, por apresentar a importante característica de frutificar na época mais seca do ano, quando os estoques de forragens naturais atingem um estágio crítico de escassez, propiciando desta forma, uma alternativa alimentar de grande valor nutricional, principalmente para a criação de caprinos e bovinos ${ }^{11}$. Esta planta produz grande quantidade de vagens de excelente palatabilidade e boa digestibilidade, apresentando composição química variável, que está na dependência do local onde é produzida ${ }^{12}$. A produção de vagens pode alcançar de 5 a 15 toneladas por hectare ${ }^{5}$.

A algarobeira é utilizada para a produção de madeira, carvão vegetal, estacas, álcool, melaço, alimentação animal e humana, apicultura, reflorestamento, ajardinamento e sombreamento, tornando-se, por conseguinte, uma cultura de valor econômico e social ${ }^{9,16}$. No Nordeste brasileiro, esta xerófita, introduzida no início da década de 40, com o objetivo de alimentar animais e de ser utilizada em reflorestamento, aparece atualmente como uma possível fonte de alimento alternativo para o homem ${ }^{13}$.

Comparando-se a produtividade desta leguminosa com o milho, verifica-se que o milho produz em média $600 \mathrm{~kg} / \mathrm{h}$ 
(precipitação de $700 \mathrm{~mm}$ ), enquanto que a algaroba pode variar de 3000 a $8000 \mathrm{~kg} / \mathrm{h}$, com pluviosidade de $300 \mathrm{~mm}^{11}$. Sendo assim, a vagem de algaroba serve de alimento nos meses em que há escassez de chuva por sua boa adaptação em ambientes secos e sem irrigação, fazendo com que ocorra a sua popularização no sertão nordestino. Esta leguminosa é uma fonte útil de alimentação animal, substituindo ou reduzindo, com custos mais baixos, o uso de milho, soja e trigo, os quais podem ser produzidos em escalas limitadas nas áreas do semi-árido ${ }^{8}$.

No presente trabalho objetivou-se avaliar a composição físico-química e microbiológica da farinha de algaroba, visando estabelecer suas potencialidades como matéria-prima para produção de rações animais e produtos alimentícios.

\section{Material e métodos}

Foram utilizadas vagens maduras de algaroba, cedidas pela SUPRANOR (Suprimentos de Alimentos do Nordeste S/A). As vagens foram selecionadas descartando-se as atacadas por insetos, fungos e as de pequeno desenvolvimento.

A farinha foi elaborada a partir de $10,0 \mathrm{~kg}$ de vagens, secas em estufa a $45{ }^{\circ} \mathrm{C}$ por 18 horas. As vagens inteiras foram trituradas em moinho de facas e logo após em moinho de atrito, até obtenção de um material homogêneo. Em seguida foram submetidas a uma tamisação com peneira em malha de 28 mesh com 0,59 mm de diâmetro.

As análises físico-químicas (umidade, cinzas, açúcares totais, açúcares redutores, proteína, extrato etéreo, fibras e taninos) foram realizadas de acordo com a metodologia descrita pelo INSTITUTO ADOLFO LUTZ7 .

A determinação dos tipos de açúcares predominantes na farinha de algaroba foi realizada através de Cromatografia em Camada Delgada utilizando-se placa de alumínio sílica gel $60 \mathrm{~F}_{254}$ MERCK. Na fase móvel foi utilizada solução com álcool butílico ( $40 \mathrm{~mL}$ ), acetona (50 mL), e água destilada (10 mL). Para preparação dos padrões utilizou-se glicose em água, frutose e sacarose "Merck". Utilizou-se como revelador uma solução contendo difenilamina e acetona p.a. que apresentou cor azul para glicose, vermelho para frutose e marrom para sacarose. A placa foi revelada em câmara escura com luz ultravioleta.

Foi utilizado um espectrofotômetro de absorção atômica (modelo 5100 PC, Perkin Elmer) com módulo de atomização em chama, pérola de impacto e correção de fundo com lâmpada de deutério. Misturas acetileno/ar foram empregadas nas proporções recomendadas pelo fabricante do instrumento para os diferentes elementos.

Foram realizadas as análises de detecção de coliformes a $45{ }^{\circ} \mathrm{C} . \mathrm{g}^{-1}$ (AOAC/02 986.33), Bacillus cereus.g ${ }^{-1}$ (AOAC/02 980.31), Salmonella sp..25 $\mathrm{g}^{-1}$ (AOAC/02 976.26/996.08) e bolores e leveduras.g ${ }^{-1}$ (AOAC/02 997.02)1.

\section{Resultados e discussão}

Para obtenção da farinha de algaroba foram tomadas algumas precauções quanto à temperatura e ao tempo de secagem ideal, pois quando estes fatores não são controlados adequadamente podem interferir na qualidade final da farinha, alterando a cor pelo elevado conteúdo em açúcares. O rendimento médio da farinha a partir das vagens obtidas foi de aproximadamente $35 \%$.

A composição físico-química da farinha de algaroba, em termos de umidade, açúcares totais, açúcares redutores, fibras alimentares total, proteínas, cinzas, extrato etéreo e tanino, está apresentada na Tabela 1.

Tabela 1. Composição físico-química da farinha de algaroba.

\begin{tabular}{lr}
\hline \multicolumn{1}{c}{ Análises } & g. $100 \mathrm{~g}^{-1}$ \\
\hline Umidade & $5,8 \pm 0,9$ \\
Açúcares totais & $56,5 \pm 0,4$ \\
Açúcares redutores & $4,6 \pm 0,3$ \\
Fibra alimentar total & $7,2 \pm 0,5$ \\
Proteínas & $9,0 \pm 1,5$ \\
Cinzas & $3,6 \pm 0,1$ \\
Extrato etéreo & $2,1 \pm 1,3$ \\
Tanino & $0,3 \pm 0,0$ \\
\hline
\end{tabular}

A concentração de açúcares totais na farinha de algaroba foi de 56,5 g. $100 \mathrm{~g}^{-1}$, valor que somado à concentração de fibras encontrada totaliza $63,7 \mathrm{~g} .100 \mathrm{~g}^{-1}$ de carboidratos. Este resultado é inferior ao encontrado por FIGUEIREDO ${ }^{3}$ que determinou $75,22 \%$ de carboidratos na vagem de algaroba. Esta diferença pode ocorrer devido a fatores como diferentes condições de cultivo e solo. No entanto, confirma a predominância de açúcares como principal fonte de nutrientes neste produto. Quanto aos tipos de açúcares presentes, observou-se a acentuada predominância da sacarose e a discreta presença de glicose, resultados estes confirmados por SILVA et al. ${ }^{13} \mathrm{e}$ FIGUEIREDO $^{3}$ que detectaram uma concentração de $46 \%$ e $29 \%$ de sacarose, respectivamente.

O teor de proteínas encontrado foi de 9,0 g. $100 \mathrm{~g}^{-1}$, resultado este inferior ao detectado por HOLMQUIST-DONQUIS e REY ${ }^{6}$ com 14,56 g. $100 \mathrm{~g}^{-1}$ de proteínas na vagem inteira de algaroba, e superior a FIGUEIREDO ${ }^{3}$ que detectou 5,58 g. $100 \mathrm{~g}^{-1}$.

SILVA et al. ${ }^{10}$ verificaram que a vagem de algaroba em comparação ao milho apresenta conteúdo de proteína similar, porém apresenta valor mais elevado de fibras. Os autores ainda relataram que na polpa da vagem (56\% do fruto) foram encontrados $1,6 \%$ de fibra solúvel associada a $0,88 \%$ de tanino solúvel e $31 \%$ de fibra insolúvel associada a 0,33\% de tanino condensado, resultado este semelhante ao encontrado neste trabalho, em que foi detectado $0,3 \%$ de taninos. Além disso, no endosperma da semente da algarobeira ( $7,6 \%$ do fruto), são encontrados galactomananos, compostos por $46,3 \%$ de manose e $34 \%$ de galactose, que apresentam capacidade de reter grande quantidade de água, aumentando de volume diversas vezes e formando soluções altamente viscosas ${ }^{5}$.

O teor de lipídios (extrato etéreo) encontrado foi de 2,1 g. $100 \mathrm{~g}^{-1}$, valor considerado baixo quando comparado a outras leguminosas como a soja. Este resultado foi inferior ao encontrado por HOLMQUIST-DONQUIS e REY ${ }^{6}$ com 
3,2 g. $100 \mathrm{~g}^{-1}$ e FIGUEIREDO ${ }^{3}$ que detectou 4,89 g. $100 \mathrm{~g}^{-1} \mathrm{de}$ lipídios na vagem de algaroba.

A partir do conteúdo em cinzas detectado $\left(3,6 \mathrm{~g} 100 \mathrm{~g}^{-1}\right)$ foram determinadas as concentrações de alguns dos minerais presentes na farinha de algaroba (Tabela 2). Estes resultados corroboram os achados de SILVA et al. ${ }^{12}$ cuja composição em sais minerais da farinha de algaroba foi de 3,3 g. $100 \mathrm{~g}^{-1}$.

Tabela 2. Minerais presentes na farinha de algaroba.

\begin{tabular}{lc}
\hline \multicolumn{1}{c}{ Minerais } & mg. $100 \mathrm{~g}^{-1}$ \\
\hline Cálcio (Ca) & 390,00 \\
Fósforo (P) & 749,00 \\
Magnésio (Mg) & 173,00 \\
Ferro (Fe) & 11,00 \\
Zinco ( $\mathrm{Zn})$ & 0,20 \\
Sódio (Na) & 1,20 \\
Potasio (K) & 0,66 \\
Manganês (Mn) & 0,19 \\
Silício (Si) & 0,52 \\
Alumínio (Al) & 330,00 \\
Cobre (Cu) & 32,50
\end{tabular}

Os minerais desempenham funções essenciais para o organismo dos animais e do homem, como, sua participação como componentes estruturais dos tecidos corporais (por exemplo, Ca, P), também atuam nos tecidos e fluidos corporais como eletrólitos para manutenção do equilíbrio ácido-básico, da pressão osmótica e da permeabilidade das membranas celulares $(\mathrm{Ca}, \mathrm{P}, \mathrm{Na}, \mathrm{Cl})$, e funcionam como ativadores de processos enzimáticos $(\mathrm{Cu}, \mathrm{Mn})$ ou como integrantes da estrutura de metaloenzimas $(\mathrm{Zn}, \mathrm{Mn})$ ou vitaminas $(\mathrm{Co})^{14}$.

A farinha de algaroba apresentou predominância de fósforo e cálcio, minerais importantes e considerados essenciais para o desenvolvimento humano e animal. Resultados semelhantes foram determinados por MAHGOUB et al. ${ }^{8}$, que além da predominância de fósforo e cálcio também verificaram traços de outros minerais.

Comparando-se a algaroba com outro tipo de leguminosa, observa-se que a soja apresenta uma quantidade maior de potássio do que a algaroba, por sua vez os outros minerais apresentam valores inferiores ou semelhantes ${ }^{15}$.

O mineral encontrado em maior concentração foi o fósforo (749 mg. $100 \mathrm{~g}^{-1}$ ). Resultado bastante superior ao encontrado por FIGUEIREDO ${ }^{3}$, que foi de $140 \mathrm{mg} .100 \mathrm{~g}^{-1}$. Em animais esta é a deficiência mais comum em minerais pela ocorrência de extensas áreas de pastagens deficientes em fósforo em todo o mundo, caracterizada por patologias como osteofagia, raquitismo, osteomalacia e baixos índices de fertilidade ${ }^{14}$.

A concentração de cálcio encontrada foi de $390 \mathrm{mg} .100 \mathrm{~g} \mathrm{~g}^{-1}$, valor próximo ao encontrado por FIGUEIREDO ${ }^{3} \mathrm{de}$ $410 \mathrm{mg} .100 \mathrm{~g}^{-1}$. Em animais a deficiência de cálcio ocorre normalmente quando estes se alimentam exclusivamente de concentrados ricos em fósforo (P), como suínos e aves que muitas vezes não são criados em regime de campo como os bovinos ${ }^{14}$.
Outro mineral que apresentou expressiva concentração foi o magnésio com $173 \mathrm{mg} .100 \mathrm{~g}^{-1}$, semelhante ao encontrado por FIGUEIREDO ${ }^{3}$ com 150 mg. $100 \mathrm{~g}^{-1}$. Dietas baseadas exclusivamente de leite levam a deficiência de magnésio, caracterizada por manifestações neuromusculares, por ser um alimento pobre neste mineral ${ }^{14}$. Na alimentação animal ou humana isto pode ser minimizado pela suplementação com alimentos que contenham magnésio, como, por exemplo, a adição de farinha de algaroba em rações animais ou sua aplicação em produtos alimentícios.

Os resultados da análise microbiológica estão dispostos na Tabela 3. Estes apresentaram valores inferiores aos limites estabelecidos pela Resolução - RDC $n^{\circ} 12$, de 02 de janeiro de $2001^{2}$, confirmando que o processo utilizado para produção da farinha é satisfatório do ponto de vista de segurança microbiológica.

Tabela 3. Análise microbiológica da farinha de algaroba.

\begin{tabular}{lcc}
\hline \multicolumn{1}{c}{ Microrganismos } & Resultado & $\begin{array}{c}\text { Resolução - RDC } \\
\mathrm{n}^{\circ} 12 / 2001\end{array}$ \\
\hline Salmonella sp..25 g $\mathrm{g}^{-1}$ & Ausência & Ausência \\
Coliformes a $45{ }^{\circ} \mathrm{C} \mathrm{UFC.g} \mathrm{g}^{-1}$ & 50 & $10^{2}$ \\
Bacillus cereus UFC.g & $<10$ & $3 \times 10^{3}$ \\
Bolores e leveduras UFC.g & $5,4 \times 10^{-1}$ & - \\
\hline
\end{tabular}

Estes resultados são importantes porque demonstram que o processamento para elaboração da farinha atende aos requisitos necessários para sua futura utilização na fabricação de novos produtos alimentícios.

\section{Conclusões}

Os resultados obtidos neste trabalho permitem concluir que a farinha de algaroba apresenta em sua composição uma elevada concentração de açúcares, além de outros nutrientes importantes para o desenvolvimento humano e animal, como seu conteúdo em minerais, principalmente cálcio e fósforo.

A partir dos resultados das análises microbiológicas, a farinha de algaroba apresentou resultados satisfatórios, dentro dos padrões estabelecidos pela legislação vigente, sendo considerada apropriada quanto à qualidade higiênico-sanitária.

\section{Agradecimentos}

A SUPRANOR (Suprimentos de Alimentos do Nordeste S/A) pelo fornecimento da matéria-prima utilizada nas análises e à CAPES (Coordenação de Aperfeiçoamento de Pessoal de Nível Superior) pela bolsa de doutorado cedida à primeira autora.

\section{Referências bibliográficas}

1. AOAC. Association of Official Analytical Chemists. Official Methods of Analysis of the Association of Official Analytical Chemists. 17.ed, Washington, 2002. 570 p.

2. BRASIL, Agência Nacional de Vigilância Sanitária - ANVISA. Resolução RDC $\mathrm{n}^{\circ} 12$, de 2 de janeiro de 2001, dispõe sobre o Regulamento Técnico sobre Padrões Microbiológicos para Alimentos. 
3. FIGUEIREDO, A. A. Mesquite: history, composition and food uses. Food Technology, Chicago - EUA, v. 44, n. 11, p. 118-128, 1990.

4. Algaroba, Tecnologia, Produtos e Usos - Meio Século no Brasil. Rio de Janeiro, Editora da UFRJ, 2000, 17 p.

5. FIGUEIREDO, A. A.; SCHMIDT, R. Rheological behavior of mesquite seed gum (MSG) in presence of some food ingredients. Revista Universidade Rural, Série Ciências da Vida, Rio de Janeiro, v. 20, n. 1-2, p. 17-21, 1999.

6. HOLMQUIST-DONQUIS, I.; REY, G. R. Propiedades funcionales de la proteína de cují (Prosopis juliflora). Archivos Latinoamericanos de Nutrición, Caracas - Venezuela, v. 47, n. 4, p. 343-351, 1997.

7. INSTITUTO ADOLFO LUTZ. Normas Analíticas. São Paulo: IAL, 1976. v. 1, Métodos físicos e químicos para análise de alimentos.

8. MAHGOUB, O. et al. Evaluation of Meskit (Prosopis juliflora) pods as feed for goats. Animal Feed Science and Technology. v. 121 , n. 3-4, p. 319-327, 2005.

9. PEREZ, S. C. J. A.; MORAES, J. A. P. V. Influência do estresse híbrico e do $\mathrm{pH}$ no processo germinativo da algarobeira. Pesquisa Agropecuária Brasileira, Brasília, v. 26, n. 7, p. 981-988, 1991.

10. SILVA, J. B.; BORA, P. S.; QUEIROGA NETO, V. Caracterização de Propriedades Funcionais do Isolado Protéico de sementes de Algaroba (Prosopis juliflora (SW) DC). Boletim Centro de Pesquisa e Processamento de Alimentos, Curitiba, v. 14, n. 2, p. 253-272, 1996.

11. SILVA, C. G. et al. Extração e Fermentação do Caldo de Algaroba (Prosopis juliflora (Sw) DC) para obtenção de aguardente. Revista Brasileira de Produtos Agroindustriais, Campina Grande, v. 5, n. 1, p. 51-56, 2003.

12. SILVA, L. F. et al. Efeitos da farinha de algaroba (Prosopis juliflora) durante as fases de gestação e lactação em ratas wistar. Acta Scientiarium. Biological Sciences, Maringá, v. 25, n. 2, p. 459-465, 2003.

13. SILVA, S. A. et al. Estudo termogravimétrico e calorimétrico da algaroba. Química Nova, São Paulo, v. 24, n. 4, p. 460-464, 2001.

14. TOKARNIA, C. H.; DÖBEREINER, J.; PEIXOTO, P. V. Deficiências minerais em animais de fazenda, principalmente bovinos em regime de campo. Pesquisa Veterinária Brasileira, Rio de Janeiro, v. 20, n. 3, p. 127-138, 2000.

15. VIEIRA, C. R.; CABRAL, L. C.; PAULA, A. C. O. Composição centesimal e conteúdo de aminoácidos, ácidos graxos e minerais de seis cultivares de soja destinados à alimentação humana. Pesquisa Agropecuária Brasileira, Brasília, v. 34, n. 7, Jul. 1999.

16. VIEIRA, R. L.; GUERRA, N. B.; FREITAS, E. M.. Sucedâneo do Café a partir de Prosopis juliflora D.C. Pesquisa Agropecuária Brasileira, Brasília, v. 30, n. 1, p. 121-124, jan., 1995. 